\title{
A clausal analysis of free choice demo in Japanese
}

\author{
Kimiko Nakanishi*
}

\begin{abstract}
It is commonly assumed that in Japanese, an indeterminate pronoun followed by demo (indet-demo) corresponds to free choice any in English (FC any). Based on the observation that the two has various different properties, I argue that indet-demo is not a nominal free choice item, but a concealed unconditional adjunct, corroborating the claim made by Nakanishi and Hiraiwa (2019) and Hiraiwa and Nakanishi (2020, to appear). Extending Rawlins's (2008, 2013) Hamblin analysis of unconditionals in English, I propose a compositional semantics of indet-demo that captures its semantics properties.
\end{abstract}

Keywords. free choice; indeterminates; unconditionals; free relatives; Japanese; modals; subtrigging; interrogatives; imperatives

1. Introduction. In Japanese, indeterminates like dare 'who' or nani 'what' give rise to various interpretations depending on a particle that they appear with, as in (1) (Kuroda 1965). It is generally assumed that an indeterminate followed by demo (indet-demo) in (2a) corresponds to free choice any (FC any) in (2b) (Nishigauchi 1990, among others).
a. Interrogative:
Al-wa nani-o tabe-masi-ta ka? ${ }^{1}$
Al-TOP what-ACC eat-POLITE-PAST KA
'What did Al eat?'
b. Existential: Al-wa nani-ka tabe-ta.
Al-TOP what-KA eat-PAST
'Al ate something.'
c. Negative polarity: Al-wa nani-mo tabe-nakat-ta.
Al-TOP what-MO eat-NEG-PAST
'Al didn't eat anything.'
a. Al-wa nan-demo tabe-teii. ${ }^{2,3}$
Al-TOP what-DEMO eat-may
b. Al may eat anything.

Contrary to this general assumption, I show that indet-demo has a number of properties that differ from those of FC any, and argue that this is because indet-demo is not a nominal FC item, but an unconditional adjunct, corroborating the claim made by Nakanishi and Hiraiwa (2019)

\footnotetext{
* I would like to thank Ken Hiraiwa, Ikumi Imani, Koji Kawahara, Kiyomi Kusumoto, Kenta Mizutani, David Y. Oshima, Osamu Sawada, and audiences at LSA 2021 for comments at different stages of this article. This research has been funded by the JSPS Grant-in-Aid for Scientific Research (C) (No. 20K00661). Author: Kimiko Nakanishi, Ochanomizu University (nakanishi.kimiko@ocha.ac.jp).

${ }^{1}$ Abbreviations used in this article are as follows: $\mathrm{ACC}=$ accusative, $\mathrm{COND}=$ conditional, $\mathrm{COP}=$ copula, $\mathrm{DAT}=$ dative, IMP=imperative, $\mathrm{NEG}=$ negation, $\mathrm{NOM}=$ nominative, $\mathrm{PASS}=$ passive, $\mathrm{PAST}=$ past tense, $\mathrm{POLITE}=$ polite form, $\mathrm{PRES}=$ present tense, $\mathrm{SBJV}=$ subjunctive, $\mathrm{TOP}=$ topic.

${ }^{2}$ The vovel $i$ in nani gets deleted for a phonological reason.

${ }^{3}$ Indeterminates may have different pitch accents: the HL pattern with nani in (1a) and (1b), and the LH pattern with nani in (1c). Both HL and LH patterns are available with nan(i) in (2a), although there seems to be a preference for the LH pattern. Hiraiwa (2017) argues that the difference in pitch accent is a reflection of different syntactic structures. See footnote 10 for further discussion.
} 
and Hiraiwa and Nakanishi (2020, to appear). Furthermore, based on Rawlins's (2008, 2013) analysis of unconditionals in English (e.g. Whatever Beth cooks, Al will be pleased), this article provides a compositional semantics of indet-demo where (2a) has the structure in (3) with two pros, one in the subject position in the unconditional clause and the other in the argument position in the main clause where nan-demo appears on the surface (see section 3.2 for details).

$$
\begin{aligned}
& \text { [pro nan(i) de ar-ter mo] Al-wa pro tabe-teii } \\
& \text { what COP exist-COND MO Al-TOP } \\
& \text { 'Whatever (it) is, Al may eat (it).' }
\end{aligned}
$$

The structure of the article is as follows. Section 2 presents empirical observations that indet-demo and FC any have various different properties. Section 3 establishes the claim that indetdemo is a concealed unconditional clause. Based on this claim, section 4 provides a compositional analysis of indet-demo. Section 5 shows that the proposed analysis can account for the properties of indet-demo presented in section 2. Section 6 examines the possibility of treating indet-demo as a free relative (e.g. Al will eat whatever Beth cooks). Section 7 concludes the article.

2. Differences between indet-demo and FC any. FC any is known to have a restricted distribution (Horn 1972, Ladusaw 1979, Carlson 1981, among others). In particular, it is acceptable in possibility sentences, as in (2b) above, but not in necessity and episodic sentences, as in (4b) and (5b), respectively. In contrast, indet-demo has no distributional restrictions; it is fine in possibility (2a), necessity (4a), and episodic sentences (5a).
a. Al-wa nan-demo tabe-nebanaranai. Al-TOP what-DEMO eat-must
b. *Al must eat anything.
a. Kinoo Al-wa nan-demo tabe-ta. yesterday Al-TOP what-DEMO eat-PAST
b. *Yesterday $\mathrm{Al}$ ate anything.

However, as exemplified in (6b) and (7b), FC any becomes acceptable in necessity and episodic sentences when an appropriate modifier is present (LeGrand's (1975) subtrigging effects) (Dayal 1998, 2004, 2009, 2013, Aloni 2007a, among others). The corresponding examples of indet-demo are also acceptable, as shown in (6a) and (7a), but these sentences are acceptable even without modifiers, as we have seen in (4a) and (5a) above. ${ }^{4}$
a. Al-wa Beth-ga tuku-ru mono-o nan-demo tabe-nebanaranai. Al-TOP Beth-NOM make-PRES thing-ACC what-DEMO eat-must
b. Al must eat anything that Beth cooks.
a. Al-wa Beth-ga tuku-tta mono-o nan-demo tabe-ta. Al-TOP Beth-NOM make-PAST thing-ACC what-DEMO eat-PAST
b. Al ate anything that Beth cooked.

Another difference comes from the availability of non-iterative readings. Dayal $(1998,2004)$ observes that any favors iterative readings, as in (8a), but iterativity is not a necessary condition, as in (8b) (see also Jayez and Tovena 2005). In contrast, indet-demo requires iterative readings, as in (9), which corresponds to (8).

\footnotetext{
${ }^{4}$ To be precise, (6a) and (7a) are not genuine examples of subtrigging. I will come back to this point in section 5.
} 
(8) a. Mary sang for anyone who wanted to hear her.

(Dayal 1998: 465)

b. Anybody who was there at that time died in the blast.

(Dayal 2004: 16)

a. Mary-wa uta-o kiki-tagat-ta dare-no tame ni-demo uta-ta. Mary-TOP song-ACC hear-want-PAST who-for-DEMO sing-PAST

b.??Sono toki sokoni i-ta hito-wa dare-demo bakuhatu-de sin-da. That time there be-PAST person-TOP who-DEMO blast-by die-PAST

There is yet another difference between the two. In imperatives, FC any can be universal, as in (10a), or it can be existential in some context, as in (10b) (Horn 1972, LeGrand 1974, Carlson 1981, Dayal 1998, Giannakidou 2001, Chierchia 2006, Aloni 2007b). In contrast, indet-demo only permits universal readings; while (11a) has the same universal reading as the corresponding English example, (11b) is odd under an intended existential reading. However, (11b) can be used to express a rather unnatural reading where the addressee is requested to press keys indifferently.
a. Confiscate any liquor.
$\forall$
(Dayal 1998: 461)
b. Press any key to continue.
$\exists$
(Giannakidou 2001: 660)
a. Dono sake-demo bossyuusi-te kudasai. $\quad \forall$ which liquor-DEMO confiscate-IMP
b. Dono kii-demo osi-te kudasai. which key-DEMO press-IMP

The differences presented so far suggest that indet-demo cannot be a simple counterpart of FC any. Then the questions arise as to what it is and what accounts for its properties, which I turn next.

3. Indet-demo as a concealed unconditional clause. In order to address, I establish the claim that indet-demo is a concealed unconditional clause, building on the proposal made by Nakanishi and Hiraiwa (2019) and Hiraiwa and Nakanishi (2020, to appear) (H\&N, henceforth).

3.1. INDET-DEMO AS AN UNCONDITIONAL CLAUSE. Extending Rawlins's (2008, 2013) analysis of English unconditionals such as (12a), H\&N present an analysis of Japanese unconditionals such as (12b), and further claim that their analysis of rum-of-the-mill unconditionals extends to indetdemo.

(12) a. Whatever Beth cooks, Al will be pleased.

b. Beth-ga nani-o tukut-te mo Al-wa yorokobu-daroo. Beth-NOM what-ACC make-COND MO Al-TOP please-will

In particular, $\mathrm{H} \& \mathrm{~N}$ propose that indet-demo like nan-demo is an unconditional clause with the structure in (13), which is composed of a copula verb de, an existential verb ar, and the particle mo. The existential ar undergoes ellipsis, yielding a seemingly nominal phrase nan-demo.

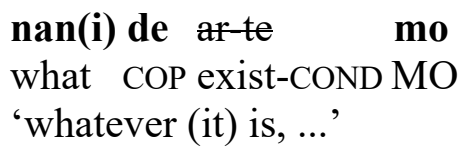

As a piece of evidence for treating indet-demo as a clause and not as a nominal element, H\&N show that indet-demo in (14b) cannot be case-marked, just like the corresponding fullfledged clause in (14a). 
a. $[\operatorname{nan}(\mathrm{i})$ de ar-te mo](*-ga/*-o) what COP exist-COND MO-NOM/-ACC 'whatever (it) is, ...' b. $[$ nan-demo $](*$-ga/*-o)

what-DEMO-NOM/-ACC

I here add another piece of evidence for H\&N's claim that indet-demo is an unconditional adjunct. Regarding standard unconditionals such as (12b), H\&N demonstrate that there are variations depending on whether the particle -mo is obligatory, prohibited, or optional, as exemplified in (15a)..$^{5}$ The same variations can be found with indet-demo, as shown in (15b), which is straightforwardly explained if indet-demo is an unconditional adjunct.
a. Beth-ga nani-o tuku $\{$-tte mo / -tta-tte / -runisiro / -rooto(-mo) $\}$
Beth-NOM what-ACC make $\{$-COND MO / -PAST-COND / -SBJV / -SBJV(-MO)\}
Al-wa yorokobu-daroo.
Al-TOP please-will
'Whatever Beth cooks, Al will be pleased.'
b. Al-wa nan $\{$-de-mo / -da-tte / -nisiro / -darooto(-mo) $\}$ tabe-teii.
Al-TOP what $\{$-COP-MO / -PAST-COND / -SBJV /-SBJV(-MO) $\}$ eat-may

Thus, I acknowledge that H\&N's analysis of indet-demo as an unconditional is on the right track, but $\mathrm{H} \& \mathrm{~N}$ fail to present a detailed compositional analysis of indet-demo. In particular, there are (at least) two issues that need to be addressed; first, H\&N's preliminary structure in (13) lacks the subject (as reflected in the English translation), and second, H\&N stay silent about how indet-demo combines with the rest of the sentence. In the following, I propose an analysis that resolve these issues.

3.2. REFINING THE STRUCTURE OF INDET-DEMO. Based on H\&N's structure in (13), I propose the structure in (16a) for (16b) ( [ ] corresponds to the unconditional clause nan-demo). ${ }^{6}$ There are two pros in the structure, one is in the subject position in the unconditional clause and the other in the argument position in the main clause where nan-demo appears on the surface (i.e., the object position in (16b)). ${ }^{7}$

$$
\begin{gathered}
\text { a. [pro nan(i) de ar-ter mo] Al-wa pro tabe-teii } \\
\text { what COP exist-COND MO Al-TOP }
\end{gathered}
$$

\footnotetext{
${ }^{5}$ The paradigm in (15a) is not exhaustive. See Hiraiwa and Nakanishi (2020), among others, for a complete list.

${ }^{6}$ The surface word order in (16b) differs from the underlying order in (16a). I assume that this order obtains as a result of scrambling the subject of the main clause over the unconditional clause. The following example, which corresponds to (12b), shows that such scrambling is freely available with regular unconditionals.

(i) Al-wai $[$ Beth-ga nani-o tukut-te mo] ti yorokobu-daroo.

Al-TOP Beth-NOM what-ACC make-COND MO please-will

'Whatever Beth cooks, Al will be pleased.'

${ }^{7}$ Indet-demo does not need to appear in the argument position, as exemplified in (i). In such a case, I remain agnostic as to whether there is a pro in the main clause (because, unlike in (16), its presence is not required by the verb).

(i) Al-wa doko-demo nemur-eru.

Al-TOP where-DEMO sleep-can

'Al can sleep anywhere.'

(ii) [pro doko de arte mo] Al-wa (pro) nemur-eru. where COP exist-COND MO Al-TOP sleep-can

'Wherever (it) is, Al can sleep (there),'

In the rest of the article, I only discuss cases like (16b) where indet-demo seemingly serves as an argument of a simplex sentence, and simply assume that the analysis of such cases extends to cases like (i) regardless of whether we posit pro in the main clause.
} 

'Whatever (it) is, Al may eat (it).'
$(=(3))$
b. Al-wa nan-demo tabe-teii.
Al-TOP what-DEMO eat-may
$(=(2 \mathrm{a}))$

Under this analysis, nan-demo in (16b) is not the internal argument of the verb, but it is an unconditional adjunct. That is, although on the surface, (16b) looks like a simplex sentence where nan-demo serves as an argument, it is actually a complex sentence where nan-demo is analyzed as an unconditional clause. The proposed analysis is corroborated by the observation in (17) that indet-demo cannot take any nominal modifiers such as adjectives and relative clauses.

a.??Al-wa oisii nan-demo tabe-teii.

Al-TOP delicious what-DEMO eat-may

(intended) 'Al may eat anything (that is) delicious.'

b.??Al-wa Beth-ga tuku-ru nan-demo tabe-teii.

Al-TOP Beth-NOM make-PRES what-DEMO eat-may

(intended) 'Al may eat anything Beth books.'

Further supporting evidence for the claim that indet-demo is not an argument comes from (18a), which demonstrates that indet-demo can co-occur with an overt argument of the verb in the main clause. (18b) shows that the nominal argument can take the relative clause, unlike (17b).
a. Al-wa ryoori-o nan-demo tabe-teii. ${ }^{8}$ Al-TOP dish-ACC what-DEMO eat-may 'Whatever (it) is, Al may eat the dish.'

b. Al-wa Beth-ga tuku-ru ryoori-o nan-demo tabe-teii. Al-TOP Beth-NOM make-PRES dish-ACC what-DEMO eat-may 'Whatever (it) is, Al may eat the dish that Beth cooks.'

Under the proposed analysis, nan-demo in (18) is an unconditional clause that is adjoined to the full-fledged sentence Al may eat the dish (that Beth cooks), as in (19). This shows that pro in the main clause in (16a) can be overtly realized.

$$
\begin{gathered}
\text { [pro nan(i) de ar-te mo] Al-wa (Beth-ga tukuru) ryoori-o tabe-teii } \\
\text { what COP exist-COND MO Al-TOP (Beth-NOM make) dish-ACC eat-may }
\end{gathered}
$$

The current analysis correctly predicts that nan-demo in (18), being an adjunct, is omissible, as illustrated in (20). Put differently, nan-demo in (18) adds to (20) a sense of indifference.
Al-wa (Beth-ga tuku-ru) ryoori-o tabe-teii.
Al-TOP Beth-NOM make-PRES dish-ACC eat-may
'Al may eat the dish (that Beth cooks).'

Furthermore, pro in the subject position of the unconditional adjunct in (16a) can also be realized on the surface. This is shown with (21a), which is minimally different from (18a) in that Beth-ga tuku-ru ryoori 'the dish that Beth cooks' takes a nominative marker in (21a), while in

\footnotetext{
${ }^{8}$ The word order is not restricted to the one presented in (18a); the examples in (i) and (ii) are equally acceptable. I assume that this is because scrambling is freely available in Japanese (cf. footnote 6).

(i) Al-wa nan-demo ryoori-o tabe-teii.

Al-TOP what-DEMO dish-ACC eat-may
} 
(18a) it takes an accusative marker. In the former case, the nominative marked element is considered to be the subject of the unconditional adjunct, as in (21b), yielding the reading 'whatever the dish that Beth cooks is'. Note that in (21a), SLRlin the main clause can also be overtly realized (e.g. by the pronoun $V R H^{\prime}$ 'it'). It follows from here that there are indet-GPR Rlsentences without SURs. ${ }^{9}$ Put differently, having SUR is not a necessary condition for legitimate indet- $G P R$ R sentences.

$$
\begin{aligned}
& \text { a. Al-wa Beth-ga tuku-ru ryoori-ga QDQGP R (sore-o) tabe-teii. }{ }^{10} \\
& \text { Al-TOP Beth-NOM make-PRES dish-NOM what-DEMO it-ACC eat-may } \\
& \text { 'Whatever the dish that Beth cooks is, Al may eat (it).' }
\end{aligned}
$$

b. [Beth-ga tukuru ryoori-ga QDQDIRGH ar-te P R] Al-wa (sore-o) tabe-teii Beth-NOM make dish-NOM what COP exist-COND MO Al-TOP it-ACC eat-may

From a semantic perspective, if the unconditional analysis of indet- $G P R$ lis on the right track, sentences with indet- $G P R$ such as (16b) and (18a) are expected to have properties that are characteristics of unconditionals. Rawlins $(2008,2013)$ observes that unconditionals in English express an implication of relational indifference. For example, (12a) expresses that, relative to whether Al will be pleased, it doesn't matter what Beth cooks. He also claims that the main clause (or the consequent of the unconditional) is entailed by an unconditional adjunct. For instance, (12a) entails that Al will be pleased. I submit that the sentence with indet- $C P$ R Thave both of these properties. For example, (18b) expresses that, relative to whether Al may eat the dish that Beth cooks, it doesn't matter what she cooks, and also it entails that Al may eat the dish that Beth cooks.

Rawlins argues that these two properties, namely, relational indifference and consequent entailment, are derived compositionally from the interpretation of unconditionals (see section 4 for details). As indet- $G P$ R has the same characteristic properties of unconditionals, in the following, I extend Rawlins's analysis to indet- $G P R$.

QT \$ IFRP SRMWRQDODQDOUVRIIQGHMGP R Rawlins (2008, 2013) presents a Hamblin (1973) analysis of unconditionals based on the insight that unconditionals are a conjunction of condi-

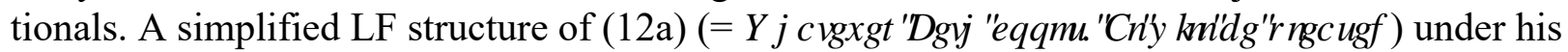
analysis is provided in (22).

\footnotetext{
${ }^{9}$ Examples such as (21a) may be taken as a piece of evidence against the view that indet- $G P$ Rlis analyzed on a par with correlatives in languages like Hindi. It has been observed that correlatives require the presence of a proform in the main clause and that there is some restriction on what kind of proform is permitted (Dayal 1996, among others). In (16a), I proposed that the adjoined unconditional indet-GHP Rrequires the presence of SLRlin the main clause. However, (21a) shows that the proform in the main clause is not restricted to $S L R$; it can be realized by a pronoun like VRUH' 'it'. [Note furthermore that VRUHcan be replaced with other expressions such as VRQRIWEEHPRQR]'that food'. The lack of restriction on a proform in the main clause makes indet- $G P R$ look different from correlatives.

${ }^{10}$ As noted in footnote 3, QDQLLCin QDQQGP Rlmay have either the LH or HL pitch accent pattern, whereas QDQLLin (21a)[must have the HL pattern. Note that when QDQLLLis followed by a copula, as in (21b), the indeterminate necessarily has the HL pattern. Thus, we may take the HL pattern in (21a) as a piece of evidence for the underlying clausal structure in (21b). However, this would wrongly predict that QDQGP Rlshould always have the HL pattern: in the proposed analysis, $Q D Q G P P R$ is derived from the clausal structure in (16a), which is like (21b) except that the subject SLRlin the unconditional clause remains covert. I here hypothesize that the LH pattern reflects a grammaticized lexical entry of indet- $G P R$. That is, indet- $G P R$ Rlmay undergo a grammaticalization process and develop into a (seemingly) nominal lexical item. Presumably, the process is easier to apply to indet- $G P R$ without an overt subject $(=(16 a))$ than to the one with the subject $(=(21 b))$. This explains why indet- $G P R$ Rlis often considered to be a nominal FC item, as discussed in section 1.
} 
[ $\forall[$ [ Q [CP whatever Beth cooks ] ] [IP All will be pleased ] ] ]

In a Hamblin semantics, all expressions denote sets. While most lexical items denote singleton sets whose sole member is their usual denotations, as in (23a) and (23b), ZKlitems denote sets of individual alternatives, as in $(23 \mathrm{c}) .{ }^{11}$ The alternatives introduced by indeterminates combine with the denotations of other lexical items via pointwise functional application. ${ }^{12}$ In our case at hand, the denotation of ZKDWAH $] \%$ MKKFRRMLis the set of propositions \{that Beth cooks meat, that Beth cooks fish, ... $\}$, as in (23d).
a. $\llbracket \% \mathbf{H M} \rrbracket=\{$ Beth $\}$
b. $\llbracket \mathbf{F R R N} \rrbracket=\left\{\lambda \mathrm{x} \lambda \mathrm{y} \lambda \mathrm{w}^{\prime} . \mathrm{y}\right.$ cooks $\mathrm{x}$ in $\left.\mathrm{w}^{\prime}\right\}$
c. $\llbracket \mathbf{Z K D W}=\llbracket \mathbf{Z} \mathbf{K D M M H} \rrbracket=\left\{\mathrm{x} \in \mathrm{D}_{\mathrm{e}}\right.$ : $\mathrm{x}$ is non-human in $\left.\mathrm{w}\right\}$
d. $\quad$ [ZKDWMH $] \%$ HMFRRM $]=\left\{\mathrm{p}: \exists x\left[\mathrm{x}\right.\right.$ is non-human in $\mathrm{w} \& \mathrm{p}=\lambda \mathrm{w}^{\prime} . \mathrm{B}$ cooks $\mathrm{x}$ in $\left.\left.\mathrm{w}^{\prime}\right]\right\}$

Based on a number of diagnostics (see Rawlins 2013: section 3.1), Rawlins claims that an unconditional adjunct like $Z K D W A H \square \%$ MKIFRRWis an interrogative clause, and that a question operator is syntactically present within the unconditional clause, as in (22). His definition of the question operator is given in (24), where $\mathrm{cs}_{\mathrm{c}}$ stands for the context set provided by the input context of internpreation c (Rawlins 2013: 138). Truth-conditionally, the operator simply lets alternatives through, but it introduces exhaustivity and mutual exclusivity presuppositions.

$\llbracket Q \alpha \rrbracket^{\mathrm{c}}=\llbracket \alpha \rrbracket^{\mathrm{c}}$

defined for $\mathrm{w}, \mathrm{g}, \alpha$ only if $\llbracket \alpha \rrbracket^{\mathrm{w}, \mathrm{g}} \subseteq \mathrm{D}_{<\mathrm{s}, \mathrm{t}}$ and

(i) $\forall \mathrm{w} \in \mathrm{cs}_{\mathrm{c}}: \exists \mathrm{p} \in \llbracket \alpha \rrbracket^{\mathrm{c}}: \mathrm{p}(\mathrm{w})=1$

(exhaustivity)

(ii) $\forall \mathrm{p}, \mathrm{p}^{\prime} \in \llbracket \alpha \rrbracket^{\mathrm{c}}:\left(\mathrm{p} \neq \mathrm{p}^{\prime}\right) \rightarrow \neg \exists \mathrm{w} \in \mathrm{cs}_{\mathrm{c}}:\left(\mathrm{p}(\mathrm{w}) \wedge \mathrm{p}^{\prime}(\mathrm{w})\right)$

(mutual exclusivity)

When (23d) combines with (24), the set of propositions \{that Beth cooks meat, that Beth cooks fish, ... $\}$ gets augmented with the two presuppositions, which ensures that every world in the context set involves exactly one alternative and that there are no worlds where multiple alternatives hold.

Rawlins further argues that each alternative in the unconditional adjunct provides a domain restriction to the modal in the main clause, which yields a set of conditionals whose antecedent and consequent are the alternative in the unconditional adjunct and the main clause, respectively. In our case, we obtain a set of conditionals (if Beth cooks meat Al will be pleased, if Beth cooks fish Al will be pleased, ... . This cannot be the final denotation of (12a), however, because in Hamblin's system, a declarative sentence must denote a singleton set. Rawlins suggests that a default universal operator in (25) is inserted in the LF of an unconditional, as in (22) (see also Menéndez-Benito 2010). As a result, (12a) denotes a singleton whose sole member is the conjunction of conditionals \{if Beth cooks meat Al will be pleased, and if Beth cooks fish Al will be pleased, and .... .

$$
\llbracket \forall \alpha \rrbracket^{\mathrm{w}, \mathrm{g}}=\left\{\lambda \mathrm{w}^{\prime} . \forall \mathrm{p}\left[\mathrm{p} \in \llbracket \alpha \rrbracket^{\mathrm{w}, \mathrm{g}} \rightarrow \mathrm{p}\left(\mathrm{w}^{\prime}\right)=1\right]\right\}
$$

(Kratzer and Shimoyama 2002)

\footnotetext{
${ }^{11}$ Rawlins (2013: section 4.3) claims that $-H H H$ is responsible for introducing an ignorance presupposition, which I put aside in this paper.]

${ }^{12}$ The definition of Hamblin Functional Application is provided below:

(i) If $\alpha$ is a branching node with daughters $\beta$ and $\gamma$, and $\llbracket \beta \rrbracket^{\mathrm{w}, \mathrm{g}} \subseteq \mathrm{D}_{\sigma}$ and $\llbracket \gamma \rrbracket^{\mathrm{w}, \mathrm{g}} \subseteq \mathrm{D}_{<\sigma \tau>}$, then

$\llbracket \alpha \rrbracket^{\mathrm{w}, \mathrm{g}}=\left\{\mathrm{a} \in \mathrm{D}_{\tau}: \exists \mathrm{b} \exists \mathrm{c}\left[\mathrm{b} \in \llbracket\left[\beta \rrbracket^{\mathrm{w}, \mathrm{g}} \& \mathrm{c} \in \llbracket\left[\gamma \rrbracket^{\mathrm{w}, \mathrm{g}} \& \mathrm{a}=\mathrm{c}(\mathrm{b})\right]\right\}\right.\right.$

(Kratzer and Shimoyama 2002)
} 
In this analysis, unconditional adjuncts provide a jointly exhaustive set of restrictions to a modal operator in the main clause. This amounts to the relational indifference implication; we try out all domain restrictions for a modal, and find that the modal claim is always true. Consequent entailment also follows from this semantics; under the derived truth conditions, Al will be pleased under any condition.

Turning now to Japanese, H\&N provide syntactic arguments that Japanese unconditionals such as (12b) have interrogative adjuncts just like English unconditionals. ${ }^{13}$ I submit that indet$G P R$ such as (26b), repeated from above, is also an interrogative clause, assuming that it has the same syntactic structure as typical unconditional adjuncts, as proposed in (26a). As for the semantics of indeterminates, it is generally assumed that indeterminates denote a set of individuals just like ZKlitems in English (Shimoyama 2001, 2006). It follows then that Rawlins's Hamblin analysis of English unconditionals straightforwardly extends to sentences with indet- $G P R$.
a. [SUR QDQDLGH ar-te
P R] Al-wa SUR tabe-teii
what COP exist-COND MO Al-TOP eat-may
'Whatever (it) is, Al may eat (it).'
b. Al-wa QDQGP RUltabe-teii.
Al-TOP what-DEMO eat-may

Under the proposed analysis, what at first looks specific to indet- $G P R$ Rlsentences is the presence of two SURs in (26a) (which can be overt, as shown in (18) and (21)), one as the subject of the unconditional adjunct, and the other as the argument in place of where indet-GP Rlappears. English unconditionals may have these SURs in the form of overt pronouns, but not always so. (27a), repeated from earlier, is a typical example of unconditionals without any pronouns, and (27b) is an unconditional with a pronoun in the argument position in the main clause. ${ }^{14}(27 \mathrm{~b})$ can be further paraphrased to $(27 \mathrm{c})$, in which case the relative clause WDW/AMKRRRMlis omissible when it is recoverable from the context. (27c) is reminiscent to the indet-GP Rlsentence in (26a).

a. Whatever Beth cooks, Al will be pleased.

b. Whatever Beth cooks, Al may eat it.

c. Whatever it is (that Beth cooks), Al may eat it.

The question then is how to analyze SURs (or overt pronouns in English). As Hirsch (2016) points out, the pronoun in the main clause in $(27 \mathrm{~b})$ has the interpretation that co-varies with that

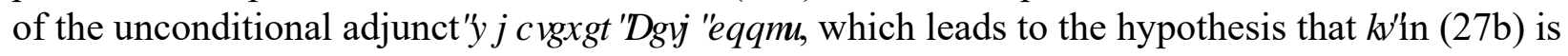
an individual variable bound by ZKDWAHVO $A M K F R R W$. However, Hirsch correctly claims that this hypothesis is incompatible with Rawlins's analysis where the unconditional adjunct is a set of propositions, and thus the adjunct cannot serve as a binder of an individual variable. To resolve this problem, Hirsch argues that LWh (27b) is an E-type pronoun with the denotation in (28), where the world variable is bound by the modal in the main clause. ${ }^{15}$

\footnotetext{
${ }^{13}$ There are two pieces of evidence for the interrogative approach. First, the sentential disjunctive connective VRLHRP $R$ 'or', which can disjoin questions but not declaratives, can disjoin unconditional clauses. Second, the indeterminate $Q D] H$ 'why', which only has a question or an existential construal, is also licit in unconditionals. See Nakanishi and Hiraiwa (2019) for details.

${ }^{14}$ As Caponigro and Fălăuş (2018: footnote 7) notes, little attention has been paid to unconditionals like (27b) (except for Hirsch (2016), which will be discussed shortly below).

${ }^{15}$ Hirsch's (2016) ultimate goal is to unify the semantics of -HHUffree relatives like (i) with that of unconditionals like (27b). See section 6 below for a comparison between unconditionals and free relatives.
}

(i) $\mathrm{Al}$ may eat whatever Beth cooks. 
Adopting Hirsch's analysis, I claim that SURlin the argument position of the main clause is an E-type pronoun with the denotation in (29) (cf. Tomioka 2003: 326).

$$
\llbracket\left[S U R \rrbracket^{\mathrm{w}, \mathrm{g}}=\mathrm{xx} . \Pi(\mathrm{x})(\mathrm{w}) \text {, where } \Pi\right. \text { is a contextually salient property }
$$

In (21a), which corresponds to the English unconditional in (27b), SURlanaphorically refers to the dish that Beth cooks, which yields the same denotation as (28).

I further propose that SURlin the subject position of the unconditional adjunct is also an Etype pronoun with the same denotation. (18a) may be viewed as a case of cataphora where SURlin the unconditional adjunct refers to the dish that Beth cooks in the main clause, again yielding the same denotation as (28). When there is no overt cue for the reference of SURs, as in (26b), SURlin the subject position of the unconditional adjunct may refer to anything that is salient in the context (e.g., the dish that Beth cooks, the food served for dinner, the leftovers in the fridge, etc.). In this case, it is natural to assume that $S U R$ lin the main clause anaphorically refers to the same thing as SLRlin the unconditional adjunct, just like in (21a).

We are now ready to apply Rawlins's Hamblin analysis to indet- $G P R$ Rlsentences. Suppose that in (26b), SUR refers to the thing that Beth cooks. The denotation of the indeterminate is a set of individuals in (30a), and it combines with the denotation of the copula and with that of SUR. As a result, we obtain a set of propositions in (30b). When the set combines with the question operator defined in (24) above, exhaustivity and mutual exclusivity presuppositions are introduced; each proposition in (30c) is interpreted exhaustively (which is indicated by RQD), and the propositions in this set are mutually exclusive. Each proposition in (30c) provides a domain restriction to the modal in the main clause. Putting the details aside, the denotation of the entire unconditional construction is provided in (30d), where each alternative has a conditional paraphrase. In this analysis, the referent of the E-type pronoun varies between the conditionals. Finally, the universal operator in (25) combines with the set in (30d), which yields a singleton set that contains the conjunction of the propositions in (30d), as in (30e).

a. $\llbracket Q D Q M]^{\mathrm{w}, \mathrm{g}, \mathrm{c}}=\{$ meat, fish, $\ldots\}$

b. $\llbracket S L R \mathbf{Q D Q} \mathbb{D}\left[\mathbf{G H a r}\right.$ te $\mathbf{P} \mathbf{R} \rrbracket^{\mathrm{w}, \mathrm{g}, \mathrm{c}}=\left\{\right.$ the thing that Beth cooks in $\mathrm{w}^{\prime}$ is meat in $\mathrm{w}^{\prime}$, the thing that Beth cooks in w' is fish in w', ...

c. $\llbracket Q \rrbracket^{\mathrm{w}, \mathrm{g}, \mathrm{c}}\left(\llbracket \mathbf{Q D Q} \mathbf{G P} \mathbf{R} \rrbracket^{\mathrm{w}, \mathrm{g}, \mathrm{c}}\right)=\left\{\right.$ the thing that Beth cooks in $\mathrm{w}^{\prime}$ is only meat, the thing that Beth cooks in w' is only fish, ...

d. \{ if the thing that Beth cooks in w' is only meat in w', Al may eat the thing that Beth cooks in w' (= the meat), the thing that Beth cooks in w' is only fish in w', Al may eat the thing that Beth cooks in w' (= the fish), ...

e. $\{$ if the thing that Beth cooks in w' is only meat in w', Al may eat the meat in w', and if the thing that Beth cooks in w' is only fish in w', Al will eat the fish in w', and ... $\}$

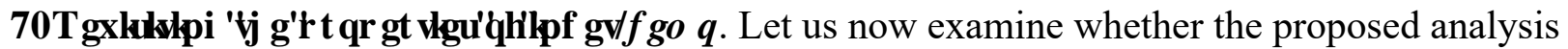
is capable of explaining the semantic properties of indet- $G P R$ discussed in section 2 . First, we have seen that indet- $G P R$ lis not subject to any distributional restrictions. In the current approach, a sentence with indet- $G P R$ is analyzed as an unconditional construction where indet- $G P R$ serves as an unconditional adjunct. Then the question is whether the main clause of unconditional constructions in general can be a possibility, a necessity, or an episodic sentence. In English, any of these sentences can be the main clause of unconditionals, as exemplified in 
(31). ${ }^{16}$ The same claim holds for run-of-the-mill unconditionals in Japanese, as illustrated in (32). Thus, the proposed analysis correctly predicts that indet- $G P R$ Rlis not sensitive to the distributional restrictions.

(31) a. Whether he is sick or not, Alfonso can stay home from school. (Rawlins 2013: 126)

b. Whatever Alfonso has, he should stay home.

(IEIG: 146)

c. Last week, whoever Alfonso talked to, he got bad advice.

(IEIG 115)

Dare-ga ki-te mo Al-wa (sono hito-ni) \{at-teii / awa-nebanaranai /at-ta . who-NOM come-COND MO Al-TOP that person-DAT \{meet-may/meet-must/meet-PAST 'Whoever comes/came, Al \{may meet / must meet / met\} (that person).'

Second, indet- $G P$ R $\backslash$ does not require the presence of subtrigging. As discussed in section 3.2, indet- $G P R$, being a clause, does not take a modifier (see (17) above), and thus there is no genuine example of subtrigging that directly modifies indet- $G P R$. However, indet- $G P R$ Ran co-occur with expressions that help us identify what $S U R$ s refer to (i.e., the subject of the adjunct and the argument of the main clause in place of indet-GPR). In (33), QDQ $G P$ Rlis an unconditional ad-

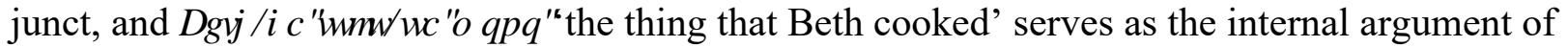
the main clause, the existence of which makes the reference of the E-type pronouns explicit. As we have seen in section 4, the resolution of the E-type pronouns is possible without the presence of such overt expressions (i.e., (33) without the bracketed expression), which account for why indet-GPRlis licit without (seeming) subtrigging.

Al-wa (Beth-ga tuku-tta mono-o) QDQGP R

Al-TOP Beth-NOM make-PAST thing-ACC what-DEMO eat-PAST

'Whatever (it) is, Al ate (the thing that Beth cooked).'

The third property is that indet- $\boldsymbol{A P}$ R Rrequires an iterative interpretation, as in (34a) (repeated from earlier). The denotation of this sentence is provided in (34b). This suggests that the blast killed a single individual each time, but such an interpretation is odd, accounting for why (34a) is infelicitous.

a.??Sono toki sokoni i-ta hito-wa GOHGP R bakuhatu-de sin-da. That time there be-PAST person-TOP who-DEMO blast-by die-PAST 'Whoever the person who was there at that time was, he died in the blast.' $\quad(=(9 \mathrm{~b}))$

b. \{if the person who was there was $\mathrm{Al}$ in w', Al died in the blast in w', and if the person who was there was Beth in w', Beth died in the blast in w', and ...

Finally, we saw that in imperatives such as (35a), indet- $G P$ Rldoes not have an existential interpretation. However, (35a) has an indifference reading (relative to pressing a key, it doesn't matter which key you choose). A plausible referent of the SURs in this sentence is the key that you choose, in which case the denotation of (35a) is $(35 b)$.

a.Ш ' RQR kii-GP R osite-kudasai. which key-DEMO press-please 'Whichever key (it) is, please press (it).'

b. \{if the key that you choose is A in w', please press that key in w', and if the key that you choose is B in w', please press that key in w', and ...

\footnotetext{
${ }^{16}$ Rawlins claims that (31c) differs from (31a) and (31b) in that the former lacks the relational indifference implication. I will discuss this point in section 6 below.
} 
As mentioned in section 3.2, one of the indispensable features of unconditionals that Rawlins's analysis successfully derives is relational indifference. Thus, the fact that (35a) has an indifference reading is taken as a piece of evidence for the claim that (35a) is an unconditional construction.

I propose here that the intended existential reading obtains when InNDW]'(lit.) good because' is added after indet- $G P R$, as in (36a) (cf. Watanabe 2013). In this case, $\mathbb{W}^{6}$ good' by itself functions as the main clause of the unconditional, which is interpreted as 'no problem' or 'it doesn't matter'. The subordinating conjunction $N D D^{6}$ 'because' lets us form two independent sentences, namely, the unconditional GRQRINWGP RULW'whichever key (it) is, no problem' and the imperative RИUAIXGDDl'please press (it)'. By using the unconditional, the speaker reassures the addressee that the choice of a key to press makes no difference. This intuition is consistent with the denotation given in (36b). The unconditional is followed by the imperative which simply requests the addressee to press the key that he chooses, which amounts to an existential interpretation of the internal argument of the verb. ${ }^{17}$

a. ' RQR kii-GP R ii kara osite-kudasai. which key-DEMO good because press-please 'Whichever key (it) is, no problem, so please press (it).'

b. \{if the key that you choose is A in w', no problem in w', and if the key that you choose is B in w', no problem in w', and ...

QT 8 QFRQGWRQDOVDQGIUHHUHDMMH. Before concluding the article, I consider a possibility of analyzing indet- $G P$ Rlas a free relative with $\square H M H U(-H M H \mathrm{UFR})$.

It has been proposed that unconditional adjuncts such as (37a) may be analyzed as $-H M H \mathbb{U F R s}$ such as (37b) (Dayal 1997, Izvorski 2000a,b, among others). The relevance of the two is apparent at least in English since the same morphology -HMHappears in the two.

a. Whatever Beth cooks, Al may eat it.

b. Al may eat whatever Beth cooks.

Rawlins presents several syntactic arguments to show that unconditionals have the structure of an interrogative, not the structure of an DHHUFR (see Rawlins 2013: section 3.1). He also discusses semantic differences between the two. In particular, he compares the nature of "indifference" in the two constructions. It has been argued that $\square H H H \mathbb{R}$ Rs may express indifference (FR-indifference, adopting Rawlins's term) (von Fintel 2000, among others). For example, (38a) means that Zack voted for the person at the top of the ballot indiscriminately. Von Fintel (2000) argues that FR-indifference is counterfactual, as exemplified by the paraphrase in (38b).

a. Zack simply voted for whoever was at the top of the ballot. (von Fintel 2000: 32)

b. Zack voted for the person that was at the top of the ballot, and if a different person had been at the top of the ballot, Zack would have voted for that person. (IEIG: 33)

${ }^{17}$ (36) is reminiscent to examples of supplemental DQ, such as (i) (Jennings 1994, Horn 2000, 2005, Giannakidou 2001, Dayal 2004, 2009, 2013); DQ lis interpreted universally, but it is separated from the imperative.

(i) Press a key, (it could be) any key.

Similarly, we may consider indet $\square G P R+\Pi \operatorname{lin}$ (36a) as a supplementary unconditional; the universal-like interpretation of the unconditional[is conjoined with the imperative. But this makes indet- $C P$ Rllook similar to FC $D Q$, which brings us to the question of whether it is possible to unify the two (see section 7 on this point). 
As briefly discussed in section 3.2, Rawlins claims that unconditionals obligatorily express an implication of relational indifference. Crucially, he presents four descriptive semantic differences between relational indifference and FR-indifference. One of the differences is that while FR-indifference is counterfactual, as shown in (38), relational indifference is not. This is illustrated with (39), which permits the continuation in (40).

Context: Alfonso talked to Joanna, Henry, and Isabella about his problem. We know this. $\checkmark$ Last week, whoever Alfonso talked to, he got bad advice.

(Rawlins 2013: 115)

$\checkmark$ But he should have talked to Charles, he would have gotten good advice.

(IEIG: 115)

Turning now to Japanese, it is not obvious whether Japanese has FRs in the first place. The answer may vary depending on the definition of FRs. If FRs require the presence of a $Z$ Kitem as a head, Japanese does not have relative clauses headed by a $Z K$ litem, hence the lack of FRs. However, if FRs are defined as headless relative clauses, Japanese does have such a configuration, which suggests the existence of FRs. Even if we abstract away from this issue and assume that indet- $G H P R$ may be analyzed as FRs, there is still a reason to believe that indet- $G P$ Rlis semantically different from FRs with respect to an implication of indifference. Just like unconditionals in English, indet- $G P$ Rlexpresses an implication of relational indifference that is not counterfactual. The indet- $\boldsymbol{G P} R$ R sentence in (41) can be followed by (42), which is unexpected if relational indifference is counterfactual.

(41) Context: $\mathrm{Al}$ attended the dinner, where chicken, lamb, and salmon were served. We know this.

$\checkmark$ Yuusyoku-de Al-wa dasa-re-ta mono-o QDQGP RUtabe-ta.

dinner-at Al-TOP serve-PASS-PAST thing-ACC what-DEMO eat-PAST

'Whatever (it) was, $\mathrm{Al}$ ate the thing that was served at the dinner.'

$\checkmark$ But if shrimp had been served, he wouldn't have eaten it. He is allergic to shellfish.

Rawlins points out that examples such as (39) are important in another respect. As discussed in section 4, in Rawlins's analysis, the relational indifference implication is derived indirectly from how each component is put together in a Hamblin semantics. This approach makes a prediction that the implication disappears when conditionals act 'non-modally' (in what he calls "material unconditionals"). This is what we observe in (39), where the context limits the relevant worlds to those compatible with the stated facts in the past. It follows that (39) makes no predictions as to what happens outside of the worlds where Alfonso didn't talk to Joanna, Henry, or Isabella. The same claim holds for (41); the indet- $G P$ Rlsentence does not imply that Al would eat what is served outside of the worlds compatible with the facts. I thus submit that the observation here further corroborates the claim that indet- $G P$ Rlis an unconditional adjunct.

૧ \&RQFOGQ $\square$ UP DUNV In this paper, I argued that indet- $G P R$, which is generally viewed as a nominal FC expression, should be analyzed as an unconditional adjunct. This analysis captures properties of indet- $G P$ R Ithat are different from those of FC expressions such as English DQ .

Crucially, I am not suggesting that unconditionals and FC expressions are completely different creatures; it is intuitively obvious that they have some fundamental properties in common. Indeed, Rawlins suggests that both unconditionals and FC effects can be meta-characterized using the notion of "orthogonality" (see Rawlins 2013: section 4.1 for details). Taking up Rawlins's insight, Szabolcsi (2019) examines Hungarian DN Uexpressions that can serve as unconditional adjuncts, FC items, and negative polarity items, and proposes a unified account of 
the Hungarian data. Also related in this context are so-called free choice free relative clauses in Greek (Giannakidou and Cheng 2016) and in Italian and Romanian (Caponigro and Fălăuş 2018). From a cross-linguistic perspective, further investigation is needed to evaluate whether it is possible to unify unconditionals and FCIs (as well as negative polarity items; see Chierchia 2006), and to determine what expressions and constructions fall under the same rubric.

\section{References}

Aloni, Maria. 2007a. Free choice and exhaustification: An account of subtrigging effects. Proceedings of Sinn und Bedeutung 11. 16-30. https://doi.org/10.18148/sub/2007.v11i0.628.

Aloni, Maria. 2007b. Free choice, modals, and imperatives. Natural Language Semantics 15. 6594. https://doi.org/10.1007/s11050-007-9010-2.

Caponigro, Ivano \& Anamaria Fălăuş. 2018. Free choice free relative clauses in Italian and Romanian. Natural Language \& Linguistic Theory 38. 323-363. https://doi.org/10.1007/s11049-017-9375-y.

Carlson, Greg. 1981. Distribution of free-choice any. Proceedings of Chicago Linguistics Society (CLS) 17.8-23.

Chierchia, Gennaro. 2006. Broaden your views: Implicatures of domain widening and the "logicality" of language. Linguistic Inquiry 37. 535-590.

https://doi.org/10.1162/ling.2006.37.4.535.

Dayal, Veneeta. 1996. Locality in WH quantification: Questions and relative clauses in Hindi (Studies in Linguistics and Philosophy). Dordrecht: Kluwer.

Dayal, Veneeta. 1997. Free relatives and ever: Identity and free choice readings. Semantics and

Linguistic Theory (SALT) 7.99-116. https://doi.org/10.3765/salt.v7i0.2787.

Dayal, Veneeta. 1998. Any as inherently modal. Linguistics and Philosophy 5. 433-476. https://doi.org/10.1023/A:1005494000753.

Dayal, Veneeta. 2004. The universal force of free choice any. Linguistic Variation Yearbook 540. https://doi.org/10.1075/livy.4.02day.

Dayal, Veneeta. 2009. Variation in English free choice items. In Rajat Mohanty \& Mythili Menon (eds.), Universals and variation: Proceedings of GLOW in Asia VII. 237-256. Hyderabad: EFL University Press.

Dayal, Veneeta. 2013. A viability constraint on alternatives for free choice. In Anamaria Fălăuş (ed.), Alternatives in semantics, 88-122. London: Palgrave Macmillan. https://doi.org/10.1057/9781137317247_4.

von Fintel, Kai. 2000. Whatever. Semantics and Linguistic Theory (SALT) 10. 27-40. https://doi.org/10.3765/salt.v10i0.3101.

Giannakidou, Anastasia. 2001. The meaning of free choice. Linguistics and Philosophy 24. 659-735. https://doi.org/10.1023/A:1012758115458.

Giannakidou, Anastasia \& Lisa Cheng. 2006. (In)definiteness, polarity, and the role of wh-morphology in free choice. Journal of Semantics 23. 135-183. https://doi.org/10.1093/jos/ffl001.

Hamblin, Charles. 1973. Questions in Montague English. Foundations of Language 10. 41-53. https://doi.org/10.1016/B978-0-12-545850-4.50014-5.

Hiraiwa, Ken. 2017. Labeling roots: Indeterminates and particles. Proceedings of the North East Linguistic Society (NELS) 47(2). 79-88.

Hiraiwa, Ken \& Kimiko Nakanishi. 2020. Bare indeterminates in unconditionals. Proceedings of the Linguistic Society of America (PLSA) 5(1). 395-409.

https://doi.org/10.3765/plsa.v5i1.4706. 
Hiraiwa, Ken \& Kimiko Nakanishi. to appear. Japanese free choice and existential indeterminates as hidden clauses. Proceedings of the Workshop on Altaic Formal Linguistics (WAFL) 15.

Hirsch, Aron. 2016. A compositional semantics for $w h$-ever free relatives. Proceedings of Sinn und Bedeutung 20. 341-358. https://ojs.ub.uni-konstanz.de/sub/index.php/sub/article/view/268.

Horn, Laurence. 1972. On the semantics properties of logical operators in English. Los Angeles, CA: University of California, Los Angeles dissertation.

Horn, Laurence. 2000. ANY and EVER: Free choice and free relatives. Proceedings of the Israeli Association for Theoretical Linguistics (IATL) 15. 71-111.

Horn, Laurence. 2005. Airport '86 revisited: Toward a unified indefinite any. In Greg Carlson and Francis Jeffry Pelletier (eds)., Reference and quantification: The Partee effect. 179-206. Stanford, CA: CSLI.

Izvorski, Roumyana. 2000a. Free adjunct free relatives. Proceedings of the West Coast Conference on Formal Linguistics (WCCFL) 19. 232-245.

Izvorski, Roumyana. 2000b. Free relatives and related matters. Philadelphia, PA: University of Pennsylvania dissertation.

Jayez, Jacques, and Lucia Tovena. 2005. Free choiceness and non-individuation. Linguistics and Philosophy 28. 1-71. https://doi.org/10.1007/s10988-005-1072-3

Jennings, Robert. 1994. The genealogy of disjunction. New York: Oxford University Press.

Kratzer, Angelika, \& Junko Shimoyama. 2002. Indeterminate pronouns: The view from Japanese. In Yukio Otsu (ed.), Proceedings of the 3rd Tokyo Conference on Psycholinguistics. 1-25. Tokyo: Hituzi Syobo.

Kuroda, S.-Y. 1965. Generative grammatical studies in the Japanese language. Cambridge, MA: Massachusetts Institute of Technology dissertation.

Ladusaw, William. 1979. Polarity sensitivity as inherent scope relations. Austin, TX: University of Texas at Austin dissertation.

LeGrand, Jean Ehrenkranz. 1974. AND and OR: some SOMEs and all ANYs. Proceedings of Chicago Linguistics Society (CLS) 10(1). 390-401.

LeGrand, Jean Ehrenkranz. 1975. Or and any: The syntax and semantics of two logical operators. Urbana-Champaign, IL: University of Illinois dissertation.

Menéndez-Benito, Paula. 2010. On universal Free Choice items. Natural Language Semantics 18. 33-64. https://doi.org/10.1007/s11050-009-9050-x.

Nakanishi, Kimiko \& Ken Hiraiwa. 2019. Nihongo no hadaka huteego: Zyoohozyookensetu ni okeru ninka mekanizumu o toosite (Bare indeterminates in Japanese: A view from a licensing mechanism in unconditionals). In Osamu Sawada, Hideki Kishimoto, \& Ikumi Imani (eds.), Hiteehyoogen no koozoo, imi, kinoo [The structure, meaning, and function of negative expressions]. 154-179. Tokyo: Kaitakusya.

Nishigauchi, Taisuke. 1990. Quantification in the theory of grammar. Dordrecht: Kluwer Academic Publishers.

Rawlins, Kyle. 2008. (Un)conditionals: An investigation in the syntax and semantics of conditional structures. Santa Cruz, CA: University of California, Santa Cruz dissertation.

Rawlins, Kyle. 2013. (Un)conditionals. Natural Language Semantics 40.111-178. https://doi.org/10.1007/s11050-012-9087-0.

Shimoyama, Junko. 2001. WH-constructions in Japanese. Amherst, MA: University of Massachusetts at Amherst dissertation. 
Shimoyama, Junko. 2006. Indeterminate phrase quantification in Japanese. Natural Language Semantics 14. 139-73. https://doi.org/10.1007/s11050-006-0001-5.

Szabolcsi, Anna. 2019. Unconditionals and free choice unified. Semantics and Linguistic Theory (SALT) 29. 320-340. https://doi.org/10.3765/salt.v29i0.4616.

Tomioka, Satoshi. 2003. The semantics of Japanese null pronouns and its cross-linguistic implications. In Kerstin Schwabe \& Susanne Winkler (eds.), The interfaces: Deriving and interpreting omitted structures. 321-339. Amsterdam: John Benjamins. https://doi.org/10.1075/la.61.16tom.

Watanabe, Akira. 2013. Ingredients of polarity sensitivity: Bipolar items in Japanese. In KookHee Gil, Stephen Harlow \& George Tsoulas (eds.), Strategies of quantification. 189-213. Berlin: Walter de Gruyter. https://doi.org/10.1093/acprof:oso/9780199692439.003.0010. 